the real conclusions of the study are rather different from those stated.

$$
\begin{array}{r}
\text { J R JASS } \\
\text { Department of Pathology, } \\
\text { School of Medicine, } \\
\text { University of Auckland, } \\
\text { Private Bag } 92019, \\
\text { Auckland, New Zealand }
\end{array}
$$

1 Deschner EE. Early proliferative changes in gastrointestinal neoplasia. Am $\mathcal{f}$ Gastroenterol 1982; 77: 207-11.

2 Jass JR. Evolution of hereditary bowel cancer. Mutation Res 1993; 290: 13-25.

3 Nakamura S, Kino I, Baba S. Nuclear DNA content of isolated crypts of background colonic mucosa from patients with familial adenomatous polyposis and sporadic colorecta cancer. Gut 1993; 34: 1240-4.

\section{Coeliac disease and autoimmune thyroid disease}

EDITor,-In their article Counsell et al state that the association between coeliac disease and autoimmune thyroid disease is not astonishing given that the HLA haplotypes B8 and DR3 are found more commonly in both than in the general population (Gut 1994; 35: $844-6)$. Based on the results of their data obtained in patients with coeliac disease they even suggest a routine check for thyroid function at presentation and a recheck if a gluten free diet fails to repair macrocytosis or symptoms, or both.

Screening patients with autoimmune thyroid disease for coeliac disease, as it has been performed by Collin et $a l^{1}$ and by our group $^{2}$ also unveils a clinically possibly important association between the two diseases. We, therefore, agree also with their second suggestion that coeliac disease should be considered in patients with autoimmune thyroid disease.

It seems noteworthy to me, however, to point out that patients with Hashimoto's thyroiditis seem to have a higher risk of developing coeliac disease than patients with Graves' disease. Patients with coeliac disease on the other hand also seem to develop hypothyroidism (Hashimoto's ?) rather than Graves' disease. Indeed, the young woman in our series of 27 patients with Hashimoto's disease, who was found to have oligosymptomatic coeliac disease was HLA-B8, DR 3 negative. This was not surprising, as we have shown earlier ${ }^{3}$ that the goitrous variant of this disease is associated with the HLA-DR5 haplotype.

I therefore want to suggest that there must be another (additional ?) link between the two diseases. This in my view is even more plausible if you consider the reports that both, Hashimoto's thyroiditis and coeliac disease, may eventually result in lymphoma, ${ }^{45}$ whereas this has never been described in Graves' disease patients.

M WEISSEL Medical University Clinic III, Waehringer Guertel 18-20,

University of Vienna, A-1097 Vienna, Austria

1 Collin P, Salmi J, Hällström O, Reunala T, Pasternack A. Autoimmune thyroid disorders and celiac disease. Eur $\mathcal{F}$ Endocrinol 1994; 130: $137-40$

2 Weissel $\dot{M}$, Vogelsang H, Penner E, Flores J. Celiac disease in autoimmune thyroid disease. Thyroid 1993; 3 (suppl 1): T30

3 Weissel M, Höfer R, Zasmeta $H$, Mayr WR, HLA-DR and Hashimoto's thyroiditis. Tissue Antigens 1980; 16: 256-8.

4 Loughran TP jr, Kadin ME, Deeg J. T-cell intestinal lymphoma associated with celiac intestinal lymphoma associated with

5 Hamburger II, Miller JM, Kiri SR. Lymphoma of the thyroid. Ann Intern Med 1983; 99: 685-9.

\section{BOOK REVIEWS}

Infections of the gastrointestinal tract. Edited by $\mathrm{M}$ J Blaser, P D Smith, J I Ravdin, H B Greenberg, R L Guerrant. (Pp xxix+ 1578; illustrated; \$282.00.) New York: Raven Press, 1995. ISBN: 0-7817-0226-7.

Yet another massive tome on infection, this time directed solely to the gastrointestinal tract! Ten parts, 97 chapters, 162 contributors - all but 11 from North America, and the weight is $3.8 \mathrm{~kg}$.

The editors begin their preface (to a volume that they have endeavoured to make 'comprehensive and practical'): 'Gastrointestinal infections are a major cause of disease and death, particularly in the developing world'; absolutely true, but surprisingly only one of the contributors (from Peru) resides there! The goal (of their labours) is, they state 'to provide a comprehensive source that combines the scientific basis and the art of medicine relevant to enteric infections'; while also emphasising that '. . . the clinician who understands the new technologies... becomes their master, not their slave' they also write that ... there are many opportunities for simple, low-technology, low-cost approaches' for dealing with this group of infections. To keep the text to reasonable length (?), and to 'avoid dilution of interest and focus', hepatic infections are not included and should, the reader is informed, '... be treated as a separate subject'. The intended readership consists of: 'the healthcare practitioner, the clinical investigator, and all who seek not only the latest clinical details but also an understanding of the breadth and limitations of our knowledge of enteric infections'.

Part I focuses on the history and epidemiological aspects (in both developed and developing countries) of diarrhoeal disease; not surprisingly there is a good deal on cholera, and also the impact of gastrointestinal infection on the course of military campaigns both well trodden paths! Anatomy, physiology, and immunology are covered in Parts II and III; normal flora, mucins, adherence factors, fluid and electrolyte transport, mucosal IgA, secretory antibody responses to enteric pathogens, cellular immune mechanisms, and immunophysiology of mast cells are some of the subjects tackled. In Parts IV to VI major clinical syndromes are considered - both in the immunointact and immunosuppressed subject; the coverage starts with food poisoning and travellers' diarrhoea, and meanders along through enteric fever, tropical sprue, appendicitis, diverticulitis, peritonitis, and infective complications of inflammatory bowel disease; there is also a great deal on Helicobacter pylori (53 pages) and HIV infection. Microbiology, epidemiology, and pathophysiological considerations form the basis for Part VII; bacterial and fungal, viral, and parasitic (protozoan and helminthic) infections are dealt with in this order. It is noteworthy that mycobacterial disease of the gastrointestinal tract (including Mycobacterium tuberculosis - which is arguably the world's most common bacterial disease) is allocated 19 pages, whereas that on Whipple's disease gets 18 ! Perhaps the editors should have taken more time with balance and prior- ities! The protozoan sections are on the whole well done; Cyclospora cayatenensis has just about made it! In a world context, helminthic infections (not least Schistosoma spp) are a dominant and important group; may be 168 pages represents rather short shrift! The remaining three parts focus on diagnosis (laboratory, endoscopic, and radiological), therapy, and preventive strategies - including vaccination (against viruses, bacteria, and parasites). A particularly useful chapter is one devoted to the treatment of paediatric diarrhoea. Although the various parts are clearly stated in the list of contents, there is no indication of this in the text itself.

One strength of this book lies in the substantial reference lists at the end of each chapter; most are appropriate and up to date, and most (but not all) accurate. The line diagrams and half-tone photographs are of good quality; 44 colour plates are included; these range from histological, endoscopic, and parasitological figures. The index is comprehensive.

But what about other books that cover this scenario? Of the American texts, Gorbach, Bartlett and Blacklow's Infectious Diseases (1992) covers these infections well, as does the fourth edition of 'Mandell' (1995). Of British tomes, the nearest is probably Bouchier, Allan, Hodgson, and Keighley's Gastroenterology: Clinical Science and Practice 2nd ed (1993). The advantage of Blaser et al is that it is devoted in entirety to gut infections and will inevitably become the reference book for some time to come in this specific area dominated by the gastroenterologist and infectious diseases physician.

G C COOK

Drug-Induced Liver Disease. By G C Farrell. (Pp 704; illustrated; £95). Edinburgh: Longmans Group, 1994. ISBN 0-443-04368-X.

Books exist describing untoward reactions of the liver to various drugs. The largest and most comprehensive is by $\mathrm{H} \mathrm{J}$ Zimmerman (Hepatotoxicity: The Adverse Effects of Drugs and Other Chemicals on the Liver; New York: Appleton-Century Crofts, 1978) but it is sadly out of date. The book edited by B C Ch Stricker (Drug-Induced Liver Injury; 2nd edition; Amsterdam: Elsevier, 1992) is justifiably in wide use. However, the drugs scene, particularly in relation to hepatotoxicity, is changing rapidly and this book from Australia, edited by Geoffrey C Farrell is both comprehensive and timely.

The first part describes underlying concepts of drug metabolism and hepatic reactions to drugs. The role of the liver in drug metabolism is contributed by Michael Murray and biochemical mechanisms by G C Farrell. Immunological mediation of drug reactions is discussed by Ian $\mathrm{R}$ Mackay, perhaps Australia's most outstanding clinical immunologist. Pdela M Hall contributes an excellent chapter on histopathology, which includes 54 figures, many of them in colour.

Various drugs are discussed under the headings frequency, risk factors, clinical features, hepatic-histology and course, outcome, and prevention. An up to date table covering 29 pages summarises the effects of each drug alphabetically. I could not find any omissions. Even ecstasy, a currently much discussed hepatotoxin is annotated. This table, on floppy disc, is available free of charge on request by those who purchase the book. 
I would have preferred to find the references (some 3600 of them) after each chapter rather than all lumped together in 103 pages at the end of the book. It would have been easier to identify the overall bibliography for any one drug.

Among all the good things, hepatotoxicity due to unorthodox and particularly herbal remedies is clearly covered. Physicians often fail to question a patient on this aspect.

Hepatic granulomas are found in up to $10 \%$ of liver biopsy specimens. Drugs are believed to be responsible for up to one third where the cause is not evident. Twenty five foreign compounds that have been incriminated in hepatic granulomatous disease are tabulated. The authors rightly emphasise that in only a few can causality be established. The more important include allopurinol, carbamazepine, phenylbutazone, phenytoin, sulphonamides, and quinidine. The physician must be cautious in attributing hepatic granulomas to a drug reaction until the many other possibilities have been excluded.

The book is very well produced and easy to handle. Tables and figures are particularly clear and useful. It is an essential tool for hepatologists and gastroenterologists and should be available for reference in every medical library.

SHEILA SHERLOCK

\section{CORRECTION}

An error occurred in the paper by Dr Friess and others (Gut 1995; 36: 771-7). The legends to Figures 2 and 3 have been transposed.

\section{NOTES}

\section{Sir Francis Avery Jones BSG Research Award 1996}

Applications are invited by the Education Committee of the British Society of Gastroenterology who will recommend to Council the recipient of the 1996 Award. Applications (eighteen copies) should include:

(1) A manuscript (2 A4 pages only) describing the work conducted.

(2) A bibliography of relevant personal publications.

(3) An outline of the proposed content of the lecture, including title.

(4) A written statement confirming that all or a substantial part of the work has been personally conducted in the UK or Eire.

Entrants must be 40 years or less on 31 December 1996 but need not be a member of the BSG. The recipient will be required to deliver a 40 minute lecture at the Spring meeting of the Society in 1996. Applications (eighteen copies) should be made to: The Honorary Secretary, BSG, 3 St Andrews Place, London NW1 4LB by 1 December 1995.

\section{Gastrointestinal pharmacology}

The International Union of Pharmacology (IUPHAR), Gastrointestinal Pharmacology Section, will hold a symposium on Biochemical Pharmacology as an Approach to Gastrointestinal Diseases on 12-14 October
1995, in Pécs, Hungary. Further information from: Professor Dr G Mózsik, First Department of Medicine, Medical University of Pécs, PO Box 99, H-7643 Pécs, Hungary. Fax: 36-72-327-660.

\section{Travel Fellowship}

The Pancreatic Society awards annually a Travel Fellowship worth $£ 1500$ to young researchers in any field of pancreatology, to enable him or her to visit laboratories and hospitals in another country to further the Fellow's education. Applicants need not be a member of the Society.

Applications are invited from clinicians in any discipline, or basic scientists, who have demonstrated an interest and ability in pancreatic research. The purpose of the Fellowship is to visit other centres, and is not primarily designed to support research. Travel solely for the purpose of attending a conference is not supported. The closing date for applications will be 31 October 1995 Applicants should submit a curriculum vitae and a proposed itinerary. Selection will be based on an interview to be held during the Society's annual meeting on 24 November 1995. Further details from the Secretary: $\mathrm{Mr}$ Colin Johnson, University Surgical Unit, F Level, Centre Block, Southampton General Hospital, Tremona Road, Southampton SO16 6YD.

\section{Liver disease}

The Sixth Manchester Liver Symposium will be held on 6 October 1995. Full programme and registration details are available from: $\mathrm{Dr}$ T W Warnes, Liver Unit, Manchester Royal Infirmary, Oxford Road, Manchester M13 9WL. Tel: 0161-276 4316. 